\title{
Carbaryl degradation by bacterial isolates from a soil ecosystem of the Gaza Strip
}

\author{
Mazen Hamada ${ }^{1}$, Ammar Matar ${ }^{2}$ Abdallah Bashir ${ }^{3}$ \\ ${ }^{1}$ Department of Chemistry, Al Azhar University, Gaza, Palestine. \\ ${ }^{2}$ Institute of Water and Environment, Al Azhar University, Gaza, Palestine. \\ ${ }^{3}$ Department of Biology, Al Azhar University, Gaza, Palestine.
}

Submitted: November 20, 2014; Approved: May 19, 2015.

\begin{abstract}
Carbaryl is an important and widely used insecticide that pollutes soil and water systems. Bacteria from the local soil ecosystem of the Gaza Strip capable of utilizing carbaryl as the sole source of carbon and nitrogen were isolated and identified as belonging to Bacillus, Morganella, Pseudomonas, Aeromonas and Corynebacterium genera. Carbaryl biodegradation by Bacillus, Morganella and Corynebacterium isolates was analyzed in minimal liquid media supplemented with carbaryl as the only source of carbon and nitrogen. Bacillus and Morganella exhibited $94.6 \%$ and $87.3 \%$ carbaryl degradation, respectively, while Corynebacterium showed only moderate carbaryl degradation at $48.8 \%$. These results indicate that bacterial isolates from a local soil ecosystem in the Gaza Strip are able to degrade carbaryl and can be used to decrease the risk of environmental contamination by this insecticide.
\end{abstract}

Key words: biodegradation, soil bacterial isolates, carbaryl, TLC.

\section{Introduction}

Carbamate insecticide (carbaryl) is a broad spectrum insecticide that is used worldwide in the agricultural industry (Hashimoto et al., 2002). The extensive use of carbamate insecticides results in the pollution of soil and water systems, which in turn increases environmental and human health hazards (Swetha and Phale, 2005). Carbaryl is a cholinesterase inhibitor and is toxic to humans as the inhibition of this enzyme leads to an accumulation of acetylcholine at the synapses resulting in uncontrolled movements, paralysis, convulsions, and possible death (Tomlin, 2000). The United States Environmental Protection Agency (EPA) has classified carbaryl insecticides as probable human carcinogens (EPA, 2008). Human exposure to carbamate insecticides occurs via contaminated food or other routes (Gunasekara et al., 2008) and because of their potential human risk, many studies have analyzed the presence of carbaryl in fruits and food products (Fana et al., 2015).

Degradation is one of the most common methods of carbaryl elimination from soil and aqueous systems, which reduces its persistence and the associated risk of environmental contamination (Tam et al., 1987; Naqvi, 2011). Mi- croorganisms capable of degrading carbamate pesticides have received considerable attention because of their role in pesticide detoxification and elimination from soil and water systems (Naqvi et al., 2011).

The present study investigated the carbaryl degradation ability of bacteria isolated from unsterilized soils from different areas in the Gaza Strip.

\section{Materials and Methods}

\section{Chemicals and devices}

All chemicals used in this study were of analytical grade and were obtained from Merck (Darmstadt, Germany), while the nutrients and agar media were purchased from HIMEDIA (Mumbai, India). Carbaryl was obtained from Dr. Ehrenstofer GmbH (Augsburg, Germany). RPC18 Bakerbond SPE $3 \mathrm{~mL}, 500 \mathrm{mg}$ cartridges (J. T. Baker, Gross-Gerau, Germany) were used to enrich samples, UVSpectrophotometer and Dual wavelength flying spot scanning densitometer were from Hitachi (Tokyo, Japan) and the solid phase extraction (SPE) unit was from Supelco (Sigma-Aldrich, Missouri, USA). 


\section{Collection of soil samples}

Eighteen different soil samples, representative of the soil ecosystem of the Gaza Strip, were locally collected from a depth of 10-20 cm according to the European soil sampling guidelines (Theocharopoulos et al., 2001). Table 1 lists soil types and geographical location of the samples.

\section{Bacterial isolation, identification and total bacterial count}

To isolate bacteria from the collected soils, the samples were treated as previously described (Bashir, 2012). Estimation of total bacterial number and subsequent pure culture of bacteria were performed using the standard plate count method and diluted nutrient broth agar (Janssen et al., 2002). Bacterial isolates were identified using standard morphological, biochemical and culture techniques (Krieg, 1984).

\section{Pesticide degradation in solid and liquid media}

The ability of the bacterial isolates to utilize carbaryl was screened by culturing them at $37^{\circ} \mathrm{C}$ for $72 \mathrm{~h}$ on minimal agar containing $150 \mathrm{ppm}$ carbaryl as the sole source of carbon and nitrogen. Bacteria capable of utilizing carbaryl were then selected and their pesticide degradation ability was further analyzed in minimal liquid media supplemented with 150 ppm carbaryl as the sole source of carbon and nitrogen. These bacterial cultures were shaken at $37^{\circ} \mathrm{C}$ and $220 \mathrm{rpm}$ Bacterial growth and remaining carbaryl concentration were monitored at $600 \mathrm{~nm}$ and $360 \mathrm{~nm}$,respectively, as described earlier (Cullington and Walker, 1999).

\section{Solid-phase extraction (SPE) of carbaryl and thin layer chromatography}

Bakerbond SPE cartridges were pre-conditioned with $10 \mathrm{~mL}$ of methanol and $5 \mathrm{~mL}$ of water; the sample solution was introduced in the cartridge at a flow-rate of 2-3 $\mathrm{mL} / \mathrm{min}$, washed with $3 \mathrm{~mL}$ of distilled water, dried under vacuum for $20 \mathrm{~min}$, and the pesticide was finally eluted with $5 \mathrm{~mL}$ of acetonitrile. The effluent was evaporated under nitrogen gas and the residue was re-dissolved in $100 \mu \mathrm{L}$ acetonitrile (Hamada et al., 2012). Chromatographic separation was performed on $20 \mathrm{~cm}$ x $20 \mathrm{~cm}$ TLC plates precoated with a $0.2-\mathrm{mm}$ thick layer of silica gel 60 F254 (Macherey-Nagel, Germany). For quantitative analysis equal volumes of standards and samples $(2 \mu \mathrm{L})$ were applied to the plates as spots using disposable micropipettes with a distance of $2 \mathrm{~cm}$ between the spots; else the entire SPE eluate $(100 \mu \mathrm{L})$ was applied as a band using Linomat IV (Camag). Carbaryl was separated by ascending onedimensional development in a saturated chamber with ethyl acetate/ hexane $(3: 2, v / v)$, as the mobile phase. The chromatogram was developed for a distance of $10 \mathrm{~cm}$ with a run time of $15 \mathrm{~min}$. The spots or bands were located by viewing

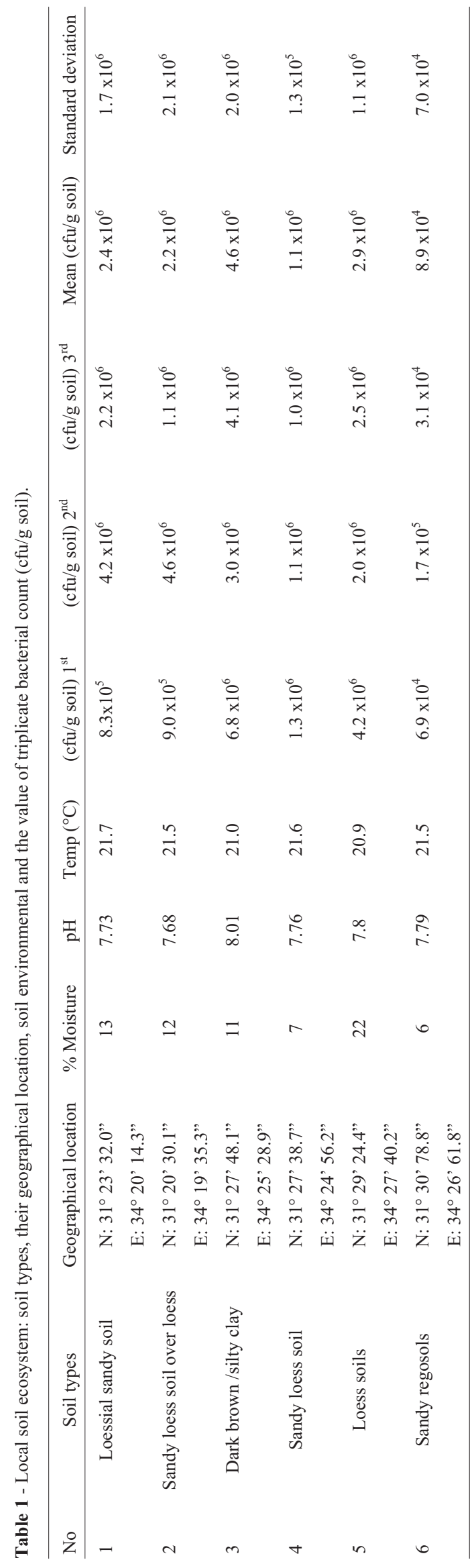


under a universal UV lamp (VilberLourmat, France) at $\lambda=254 \mathrm{~nm}$. Carbaryl concentration was determined using a Shimadzu CS-9301 dual Wavelength, flying-spot scanning densitometer in the reflectance mode using a deuterium lamp $(\lambda=250 \mathrm{~nm})$. Acquisition parameters were beam size $0.4 \mathrm{~mm} \times 16 \mathrm{~mm}$ and deuterium lamp set at zero at start with a 15-point smoothing. Calibration was done by peak area, and the peak find filter was set at 50 with resolution during data collection set at 0 . The relative peak area was calculated which is directly proportional to the remaining concentration of the pesticide.

\section{Results and Discussion}

\section{Bacteriological, physical and chemical parameters of the soil ecosystem}

Bacterial diversity was clearly observed in all five soil types representative of the soil ecosystem in the Gaza Strip. Total bacterial counts (cfu/g soil) for the soil samples are shown in Table 1. Dark brown/silty clay soil had the highest bacterial count $\left(4.64 \times 10^{6} \mathrm{cfu} \mathrm{g}^{-1}\right)$ and loessial sandy soil had a total bacterial count of $2.36 \times 10^{6} \mathrm{cfu} \mathrm{g}^{-1}$. This soil type is widely distributed in the Gaza Strip and is comparatively less polluted; therefore, we chose bacterial isolates from this sample and analyzed their ability to degrade carbaryl. The total bacterial count of sandy loess over loess soil was $2.21 \times 10^{6} \mathrm{cfu} \mathrm{g}^{-1}$ while that of loess soil was $2.92 \times 10^{6} \mathrm{cfu} \mathrm{g}^{-1}$. Both sandy loess soil and sandy regosols soil had low bacterial counts of $1.11 \times 10^{6} \mathrm{cfu} \mathrm{g}^{-1}$ and $8.9 \times 10^{4} \mathrm{cfu} \mathrm{g}^{-1}$, respectively.

The viable bacterial counts reported herein are comparable to those in earlier reports (Bashir 2012). However, these bacterial counts are about a hundred to thousand fold lower than the estimated count reported in other studies (Janssen et al., 2002; Schoenborn et al., 2004). The viable bacterial counts in the different soil types of the Gaza Strip were less than the expected bacterial count in one gram of soil. The bacterial isolates were identified via Gram staining, culture and biochemical methods (Krieg, 1984) and belonged to various genera including; Bacillus, Pseudomonas, Staphylococcus, Acinetobacter, Escherichia, and Streptomyces. The physical and chemical parameters (moisture content, $\mathrm{pH}$, and temperature) of the soil ecosystem of the Gaza Strip were found to be similar to those accepted as suitable for bacterial activity (Pietikäinen et al., 2005, Iovieno and Bååth, 2008; Rousk et al., 2010). Bacteria of the Bacillus genera that were isolated from loessial sandy soil showed the highest rate of biodegradation (Figure 1). While bacteria from all the sampled soil types were capable of carbaryl biodegradation (data not shown), the rate of biodegradation varied among the different soils types and such a marked difference in the ability to degrade different pesticides has been previously observed among the various types of soils (Bending et al., 2004; Kah et al., 2007).
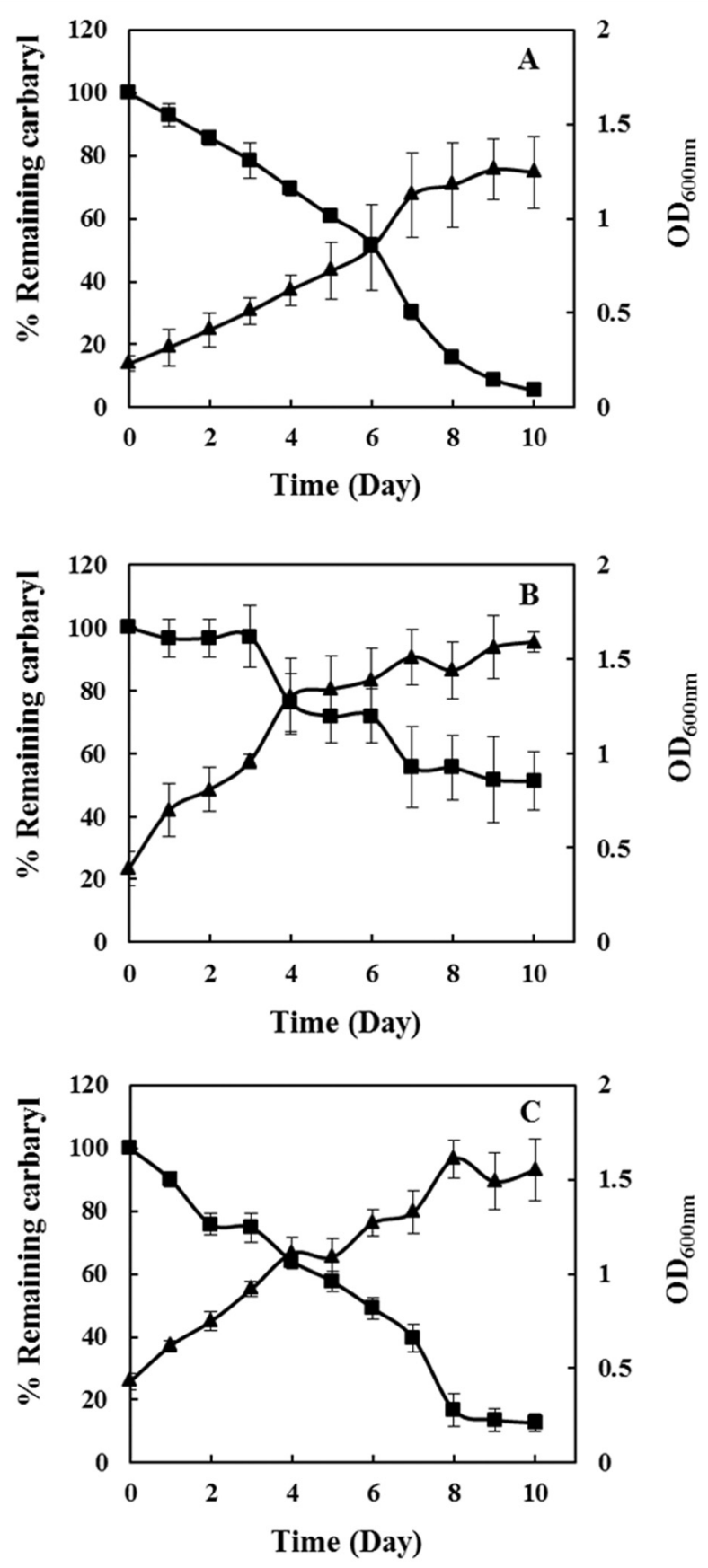

Figure 1 - Bacterial growth and percentage of carbaryl remaining in minimal liquid media. Bacterial isolates A) Bacillus B) Morganella and C) Corynebacterium were grown in liquid minimal media at initial concentration equivalent to $\mathrm{OD}_{600 \mathrm{~nm}}$ of 0.2 to 0.5 . Bacterial growth and percentage of carbaryl remaining in the media were monitored for 10 days.

\section{Carbaryl degradation activity on solid and liquid minimal media}

Large variations in growth rate among the bacterial isolates were observed when the ability to metabolize carbaryl was tested in minimal agar media. Some of the tested isolates $(25 \%)$ were unable to grow with carbaryl as the 
source of carbon and nitrogen, while the rest $(75 \%)$ showed varying degrees of growth. Bacterial growth on minimal agar media was monitored for three days and three isolates capable of utilizing carbaryl were selected for further identification. These isolates were identified as belonging to the Bacillus, Corynebacterium and Morganella genera using standard techniques and their carbaryl biodegradation capacity was further tested in liquid media. Table 2 and Figure 1 demonstrate changes in growth and remaining carbaryl percentage in M9 liquid minimal medium for all three isolates. All bacterial isolates reached maximum growth (optical density $=1.5$ ) after 10 days. At this time point, the Bacillus isolate showed greatest carbaryl degradation (98.71\%) followed by Corynebacterium (87.37\%), while Morganella showed least degradation (47.59\%). These results are similar to those reported previously and serve to confirm previous findings that soil bacteria from different genera degrade carbaryl to varying degrees (Rousseaux et al., 2001; Swetha and Phale, 2005; Uma and Sandhya, 2010).

Table 3 gives the recovery, standard deviation (SD) and relative standard deviation (RSD) of carbaryl degradation by Morganella sp. measured after optimization of SPE conditions for the enrichment of samples spiked with $150 \mathrm{ppm}$ carbaryl. The average recovery for carbaryl using SPE was $92.6 \%$ with a relative standard deviation of less than $1 \%$; these values meet the requisite conditions for quantitative determination of pesticide degradation.

The SPE extracts of days $0,2,5$ and 7 were also spotted onto the TLC plate and displayed an Rf-value of 0.7. It is important to highlight the fact that the results of carbaryl biodegradation, measured both spectrophotometrically and

Table 2 - The Spectroscopic measurement of carbaryl degradation in minimal liquid media supplemented with carbaryl as sole source of carbon and nitrogen.

\begin{tabular}{|c|c|c|c|c|c|c|c|c|c|}
\hline \multirow[t]{2}{*}{ Day } & \multicolumn{3}{|c|}{ Bacillus } & \multicolumn{3}{|c|}{ Morganella } & \multicolumn{3}{|c|}{ Corynebacterium } \\
\hline & $\mathrm{OD}_{600 \mathrm{~nm}}$ & $\mathrm{Abs}_{360 \mathrm{~nm}}$ & Remaining* (\%) & $\mathrm{OD}_{600 \mathrm{~nm}}$ & $\mathrm{Abs}_{60 \mathrm{~nm}}$ & Remaining* (\%) & $\mathrm{OD}_{600 \mathrm{~nm}}$ & $\mathrm{Abs}_{360 \mathrm{~nm}}$ & Remaining* (\%) \\
\hline 0 & 0.232 & 0.056 & 100 & 0.39 & 0.024 & 100 & 0.43 & 0.198 & 100 \\
\hline 1 & 0.318 & 0.052 & 92.9 & 0.70 & 0.023 & 96.6 & 0.60 & 0.178 & 90.0 \\
\hline 2 & 0.412 & 0.048 & 85.7 & 0.81 & 0.023 & 96.6 & 0.75 & 0.15 & 75.8 \\
\hline 3 & 0.510 & 0.044 & 78.6 & 0.96 & 0.023 & 97.1 & 0.92 & 0.148 & 74.8 \\
\hline 4 & 0.623 & 0.039 & 69.6 & 1.13 & 0.018 & 76.0 & 1.11 & 0.127 & 64.2 \\
\hline 5 & 0.724 & 0.034 & 60.7 & 1.34 & 0.017 & 71.8 & 1.09 & 0.114 & 57.6 \\
\hline 6 & 0.846 & 0.029 & 51.8 & 1.39 & 0.017 & 71.8 & 1.27 & 0.097 & 49.1 \\
\hline 7 & 1.125 & 0.017 & 30.4 & 1.51 & 0.013 & 55.7 & 1.33 & 0.078 & 39.5 \\
\hline 8 & 1.179 & 0.009 & 16.1 & 1.44 & 0.013 & 55.4 & 1.61 & 0.033 & 16.7 \\
\hline 9 & 1.260 & 0.005 & 8.9 & 1.56 & 0.012 & 51.7 & 1.49 & 0.027 & 13.7 \\
\hline 10 & 1.246 & 0.003 & 5.4 & 1.59 & 0.012 & 51.2 & 1.55 & 0.025 & 12.7 \\
\hline
\end{tabular}

*Mean of three measurements.

Table 3 - The standard deviation (SD), relative standard deviation (RSD) and recoveries percentage of the remaining carbaryl after solid phase extraction (SPE).

\begin{tabular}{|c|c|c|c|c|c|c|}
\hline Degradation time & Relative peak areas & Average & Remaining \% & $\mathrm{SD}$ & RSD \% & Recoveries \% \\
\hline \multirow[t]{3}{*}{ Zero time } & 891.37 & 891.11 & 100.00 & 0.18 & 0.020 & 92.6 \\
\hline & 894.74 & & & & & \\
\hline & 887.21 & & & & & \\
\hline \multirow[t]{3}{*}{2 days } & 858.76 & 858.73 & 96.36 & 0.02 & 0.002 & \\
\hline & 864.92 & & & & & \\
\hline & 852.52 & & & & & \\
\hline \multirow[t]{3}{*}{5 days } & 651.63 & 646.90 & 72.59 & 3.34 & 0.51 & \\
\hline & 646.95 & & & & & \\
\hline & 642.12 & & & & & \\
\hline \multirow[t]{3}{*}{7 days } & 607.72 & 433.60 & 48.65 & 2.51 & 0.41 & \\
\hline & 615.16 & & & & & \\
\hline & 610.94 & & & & & \\
\hline
\end{tabular}


by SPE, are obviously coincident and in complete agreement with each other.

\section{Conclusion}

The results presented herein show that the environmental conditions in the local soil ecosystem of the Gaza Strip are suitable for microbial growth, bacterial isolates from different genera are present, and that they are capable of degrading carbaryl to varying degrees. Bacteria of the genus Bacillus show greatest biodegradation activity. The present study also highlights the need for further studies to identify microbial populations capable of biodegrading organic components, which could efficiently be used in the bioremediation of pesticide-polluted soils. As soil intrinsic factors like organic carbon and composition of clay, silt and sand were not determined in our study; we suggest that a more detailed soil analysis should be conducted. This would provide a wealth of information on pesticide biodegradation in the soil ecosystem of the Gaza Strip, especially when it is compared with bacterial genera isolated from other soil ecosystems.

\section{References}

Bashir HA (2012) Diversity and Morphology of Bacterial Community Characterized in Topsoil Samples from the Gaza Strip, Palestine. Res J Microbiol 7:309-318.

Bending DG, Lincoln DS, Edmondson NR (2006) Spatial variation in the degradation rate of the pesticides isoproturon, azoxystrobin and diflufenican in soil and its relationship with chemical and microbial properties. Environ Pollut 139:279-287.

Cullington J, Walker A (1999) Rapid biodegradation of diuron and other phenylurea herbicides by a soil bacterium. Soil Biol Biochem 31:677-686.

Fana Y, Laia K, Rascob AB et al. (2015) Determination of carbaryl pesticide in Fuji apples using surface-enhanced Raman spectroscopy coupled with multivariate analysis. Lwt Food Sci Technol 60:352-357.

Gunasekara AS, Rubin AL, Goh KS et al. (2008) Environmental fate and toxicology of carbaryl. Rev Environ Contam Toxicol 196:95-121.

Hamada M, Abu Ghalwa N, Abu Shawish HM et al. (2012) Rapid and inexpensive densitometric method, using TLC plates, for quantification of nine pesticides in water. Pak J Chem 2:1-7.

Hashimoto M, Fukui M, Hayano K et al. (2002) Nucleotide sequence and genetic structure of a novel carbaryl hydrolase gene (cehA) from Rhizobium sp., strain AC100. Appl Environ Microb 68:1220-1227.
Janssen P, Yates P, Grinton B et al. (2002) Improved culturability of soil bacteria and isolation in pure culture of novel members of division acidobacteria, acitinobacteria, actinobacteria, protebacteria, and verrucomicrobia. Appl Environ Microb 68:2391-2396.

Kah M, Beulke S, Brown DC (2007) Factors Influencing Degradation of Pesticides in Soil. J Agric Food Chem 55:44874492.

Krieg NR (1984) Bergey's Manual of Systematic Bacteriology. $1^{\text {st }}$ ed. Williams and Wilkins, Baltimore, Vol. 1.

Naqvi T, Kanhar N, Shar A et al. (2011) Microcosm studies for biodegradation of carbaryl in soil. Pak J Bot 43:1079-1084.

Pietikäinen ABJ, Pettersson AM, Bååth E (2005) Comparison of temperature effects on soil respiration and bacterial and fungal growth rates. FEMS Microbiol Ecol 52:49-58.

Iovieno P, Bååth E (2008) Effect of drying and rewetting on bacterial growth rates in soil. FEMS Microbiol Ecol 65:400-407.

Rousk J, Bååth E, Brookes P et al. (2010) Soil bacterial and fungal communities across a $\mathrm{pH}$ gradient in an arable soil. ISME $\mathrm{J}$ 4:1340-1351.

Rousseaux S, Hartmann A, Soulas G (2001) Isolation and characterisation of new Gram-negative and Gram-positive atrazine degrading bacteria from different French soils. FEMS Microbiol Ecol 36:211-222.

Schoenborn L, Yates BE, Grinton P et al. (2004) Liquid Serial Dilution Is Inferior to Solid Media for Isolation of Cultures Representative of the Phylum-Level Diversity of Soil Bacteria. Appl Environ Microb 70:4363-4366.

Tam AC, Behki MR, Khan US (1987) Isolation and characterization of an s-ethyl-N,Ndipropylthiocarbamate-degrading Arthrobacter strain and evidence for plasmid-associated sethyl-N,N-dipropylthiocarbamate degradation, Appl Environ Microb 53:1088-1093.

Theocharopoulos S, Wagner G, Sprenqart J et al. (2001) European soil sampling guidelines for soil pollution studies. Sci Total Environ 264:51-62.

Tomlin CDS (2000) The Pesticide Manual. 12th ed. British Crop Protection Council, Surrey, pp. 133-134.

Uma B, Sandhya S (2010) Pyridine degradation and heterocyclic nitrification by Bacillus coagulans. Can J Microbiol 43:595-598.

U.S. EPA (2008) Office of Pesticide Programs. Amended Reregistration Eligibility Decision (RED) for Carbaryl. Environmental Protection Agency, Washington, DC.

Swetha VP, Phale SP (2005) Metabolism of carbaryl via 1,2Dihydroxynaphthalene by soil isolates Pseudomonas sp. strains C4, C5, and C6. Appl Environ Microb 71:5951-5956.

Associate Editor: Fernando Dini Andreote

All the content of the journal, except where otherwise noted, is licensed under a Creative Commons License CC BY-NC. 